\title{
Successful Aorta-osteal Stenting after Iatrogenic Acute Type-A Aortic Dissection during Primary Percutaneous Coronary Intervention
}

\author{
Adem Bekler ${ }^{1}$, Ali Özeren², Emine Gazi ${ }^{1}$, Ahmet Temiz $^{1}$, Burak Altun ${ }^{1}$ \\ ${ }^{1}$ Department of Cardiology, Çanakkale Onsekiz Mart University Faculty of Medicine, Çanakkale, Turkey \\ ${ }^{2}$ Department of Cardiology, Bursa Bahar Hospital, Bursa, Turkey
}

Background: Iatrogenic acute dissection of the ascending aorta following coronary angiography and percutaneous intervention is rare. This complication, if not managed urgently, can have critical results. Case Report: We present the case of a 70 year-old woman who was treated by primary percutaneous coronary intervention (PCI) of the right coronary artery (RCA) for acute inferior myocardial infarction; however, the procedure was complicated by anterograde dissection of the RCA with a simultaneous retrograde propagation to the proximal part of the ascending aorta. Successful stenting of the entry point was able to heal the RCA and restrict the retrograde propagation to the ascending aorta. The aortic dissection was monitored by means of computerised tomography and the dissection repaired itself spontaneously within a day.

Conclusion: Treatment of the aorta coronary dissection (ACD) by urgent osteal stenting is a less invasive treatment compared with surgical treatment in appropriate cases. We demonstrated that immediate osteal stenting should be performed in ACD.

Key Words: Acute myocardial infarction, aorto-coronary dissection, percutaneous coronary intervention
It has been shown that the incidence of acute dissection of the ascending aorta (AD), as a complication of diagnostic coronary angiography and percutaneous coronary intervention (PCI), is 0.03 to $0.06 \%$ (1). Trauma to the coronary ostia and interventional procedures can cause AD (2). We wanted to introduce a patient with acute inferior myocardial infarction in whom aorta-coronary dissection (ACD) developed as a complication after PCI, and in whom ACD was stented successfully and dissection propagation was limited.

\section{CASE PRESENTATION}

A 70-year old female patient applied to our hospital with chest pain. Examination of the cardiovascular system showed a blood pressure of $120 / 66 \mathrm{mmHg}$ and pulse rate of 74 beats per minute. Other systemic review did not reveal any abnormality. Electrocardiography showed ST-elevation in inferior leads and ST-depression in anteroseptal leads. She was hospitalised with a diagnosis of inferior myocardial infarction. The coronary angiography was performed quickly. Her coronary angiogram showed no significant lesions in the circumflex artery and the left anterior descending coronary artery. Also, $90 \%$ tubular stenosis was found in the proximal-portion and $100 \%$ narrowing with a thrombus mid-portion of the RCA (Figure 1). We decided to perform PCI of the proximal and mid-portion of the RCA. RCA was engaged with a JR4-6F guiding catheter (Guiding catheter, Medtronic, New York, USA). When interfering with the wire to the RCA using an intermediate wire (Intermediate wire, Simslide, Istanbul, Turkey), a dissection was apparent from the proximal part of the RCA. After the first contrast, the ACD was apparent; the ACD had spread to the RCA and AA (Figure 2). Patient rhythm showed complete block with a pulse of 32 beats per minute. Since the patient was haemodynamically unstable, a temporary pacing wire was implanted. Next, three bare-metal stents (BMS) (Bare metal stent, Simcross 3.0*25, 3.0*18, $3,5 * 28 \mathrm{~mm}$; Simeks, Istanbul, Turkey) were placed from the middle of the RCA to the ostium of the RCA. The ostium was stented after mid-distal segment stenting. After this applica-

This case was presented at the 10th Congress of Update in Cardiology and Cardiovascular Surgery, 13-16 March 2014, Antalya, Turkey.

Address for Correspondence:Adem Bekler, Department of Cardiology, Çanakkale Onsekiz Mart University Faculty of Medicine, Çanakkale, Turkey Phone: +902862635950 e-mail: adembekler27@gmail.com

Received: 12.06.2014 Accepted: 20.09.2014 • DOI: 10.5152/balkanmedj.2014.14039

Available at www.balkanmedicaljournal.org

Bekler A, Özeren A, Gazi E, Temiz A, Altun B. Successful aorta-osteal stenting after iatrogenic acute type-A aortic dissection during primary percutaneous coronary intervention. Balkan Med J 2014;31:352-5. 
tion, the instent portion was dilated using a noncompliant high pressure balloon (Noncompliant balloon, Sprinter $3.5 * 27 \mathrm{~mm}$ Medtronic, New York, USA) up to 18 atm. Follow-up angiogram revealed that there was no contrast leakage to the false lumen (Figure 3). Emergent computerised tomography (CT) after the procedure revealed intramural haematoma (IMH) formation, with contrast retention (Figure 4a, arrows). The patient had an eventless hospital course and the followup CT scan after 2 days (Figure 4b, arrows) and 3 months (Figure 4c) demonstrated complete resolution of the false lumen. Informed consent was obtained from the patient for this case report.

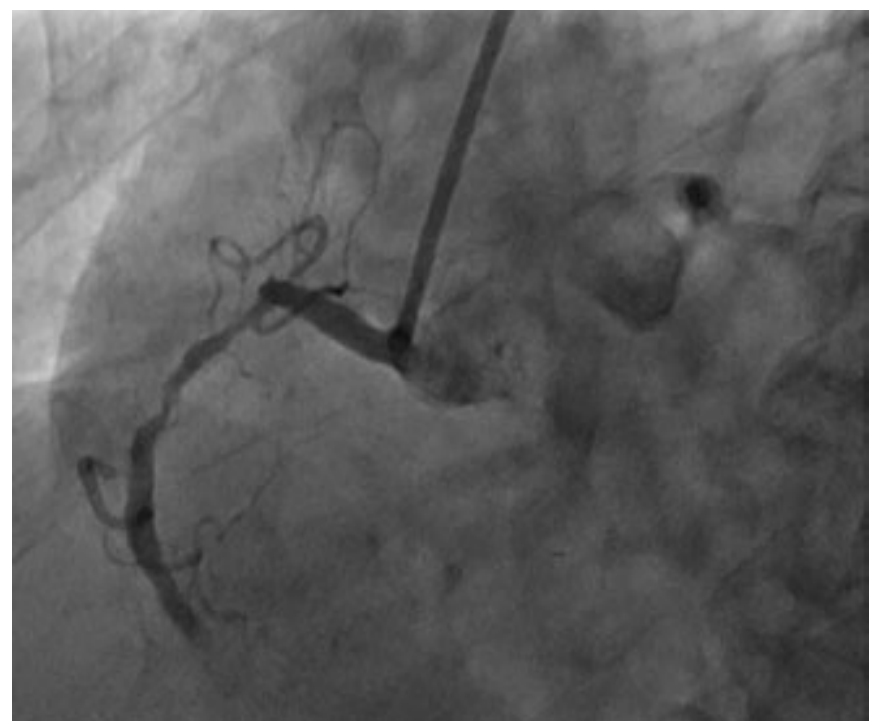

FIG. 1. Coronary angiogram showing that $90 \%$ tubular stenosis was found in the proximal-portion and $100 \%$ narrowing with a thrombus in the mid-portion of the right coronary artery

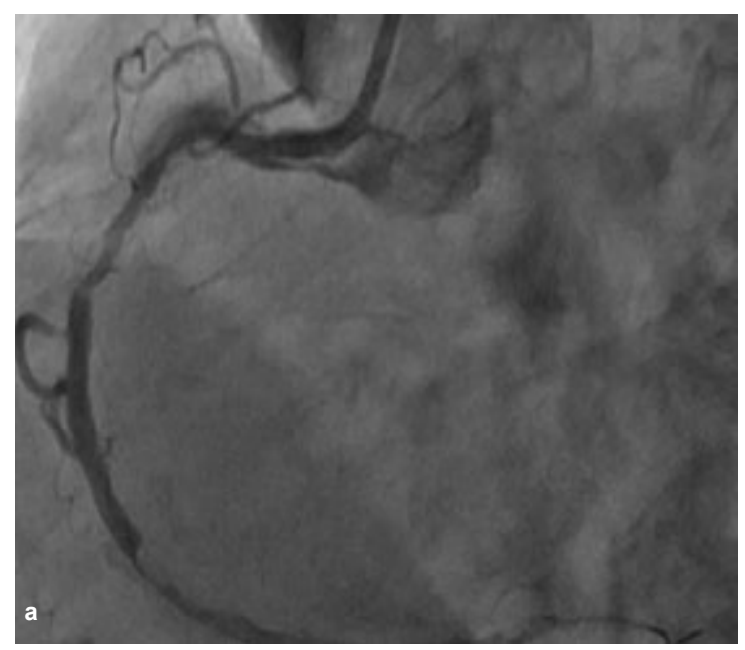

\section{DISCUSSION}

The dissection of the ascending aorta (AA) is one of the major life-threatening complications of aortic diseases. ACD is a very rare complication of coronary interventions. Trauma to the coronary ostia and interventional procedures can cause $\mathrm{AD}$ (2). In our case, dissection in the proximal part of the RCA is caused and triggered by the Intermediate Wire. Hypertension, advanced age, diabetes mellitus, history of cardiac surgery and cystic medial necrosis can be included as predisposing factors for $\operatorname{AD}(3,4)$. Goldstein et al. (5) reported that $89 \%$ of ACD is on the right side and $11 \%$ on the left side. López Mínguez et al. (6) reported that most cases of ACD are in the RCA, because the RCA has fewer smooth muscle cells and matrix type-1 collagen fibrils than the left coronary artery sinotubular junction.

Naturally, the treatment of type-A AD is surgical resection and the replacement of AA. However, emergent stenting can be used as a novel treatment modality, because it may limit the extent of dissection in some iatrogenic ACD cases, and eliminate any further interventions $(2,7)$. As in our case, surgical treatment of $\mathrm{AD}$ due to interventions in patients with acute coronary syndrome can be quite dangerous, because $\mathrm{AD}$ propagation may more often be due to the administration of heparin and anti-platelet drugs during PCI. Therefore, in such cases, coronary stenting when ACD dissection develops can be quite helpful and therapeutic, because it closes entry and therefore prevents the spread of dissection. In some cases, the $\mathrm{ACD}$ can be monitored conservatively, and in others, surgery may be unavoidable.

Tanase et al. (8) performed emergency stenting in five of the eight patients in whom ACD developed. Two patients

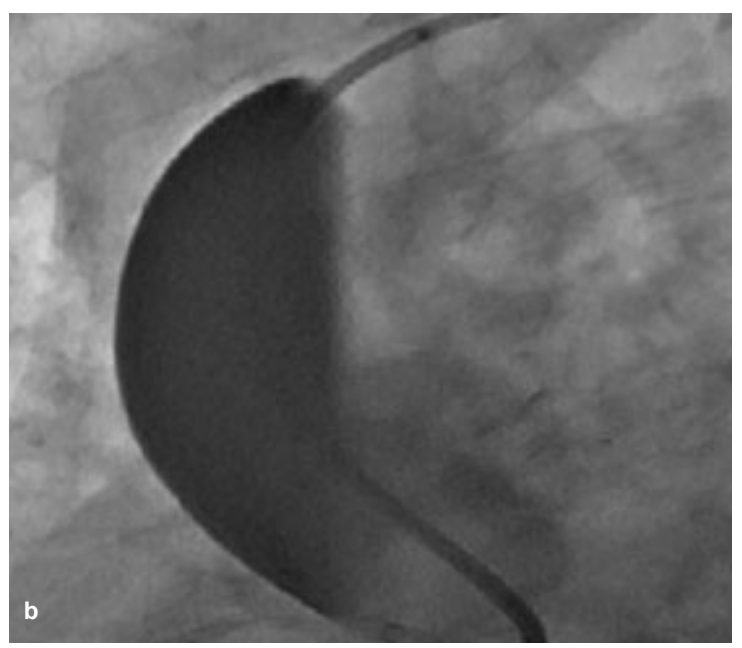

FIG. 2. a, b. TCoronary angiogram showing the dissection propagated to the right coronary sinus (a). Coronary angiogram showing the dissection propagated to ascending aorta (b). 

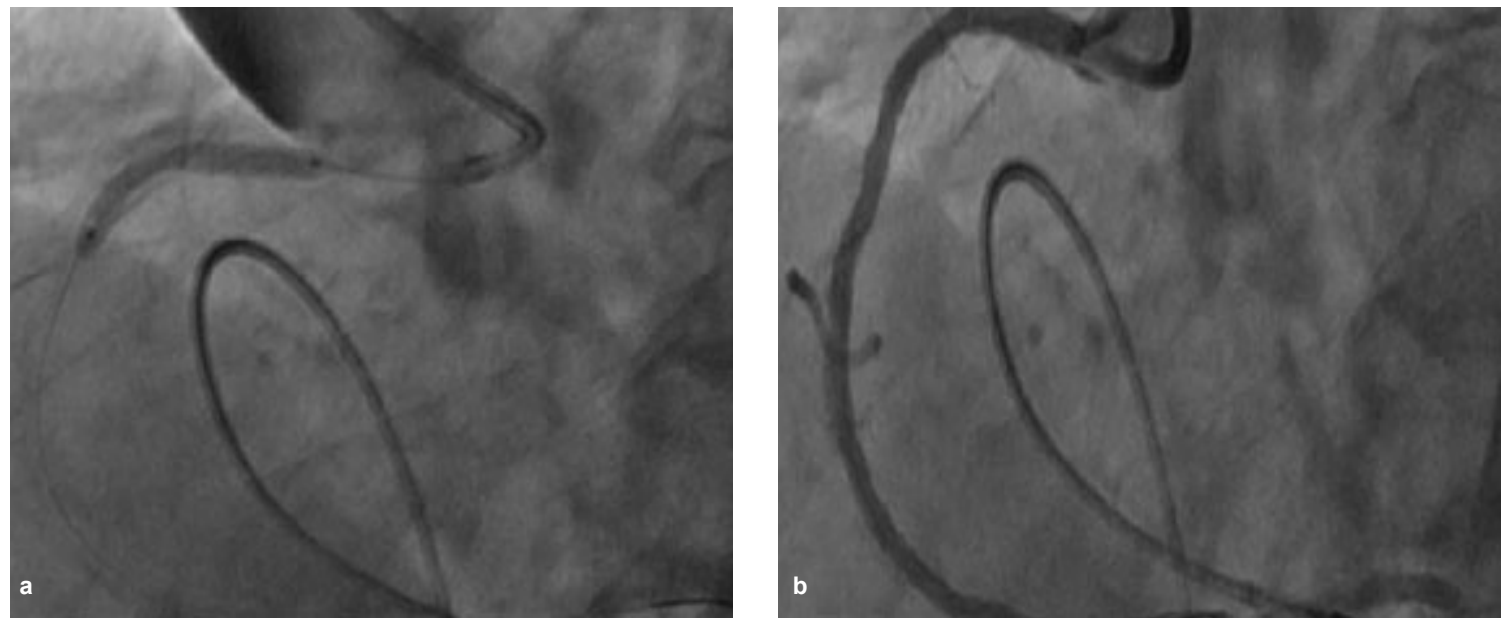

FIG. 3. a, b. The aorto-coronary dissection stenting of the entry point to the right coronary artery (a). Successful stenting of the entry point to heal the right coronary artery and to restrict the retrograde propagation to the ascending aorta (b).
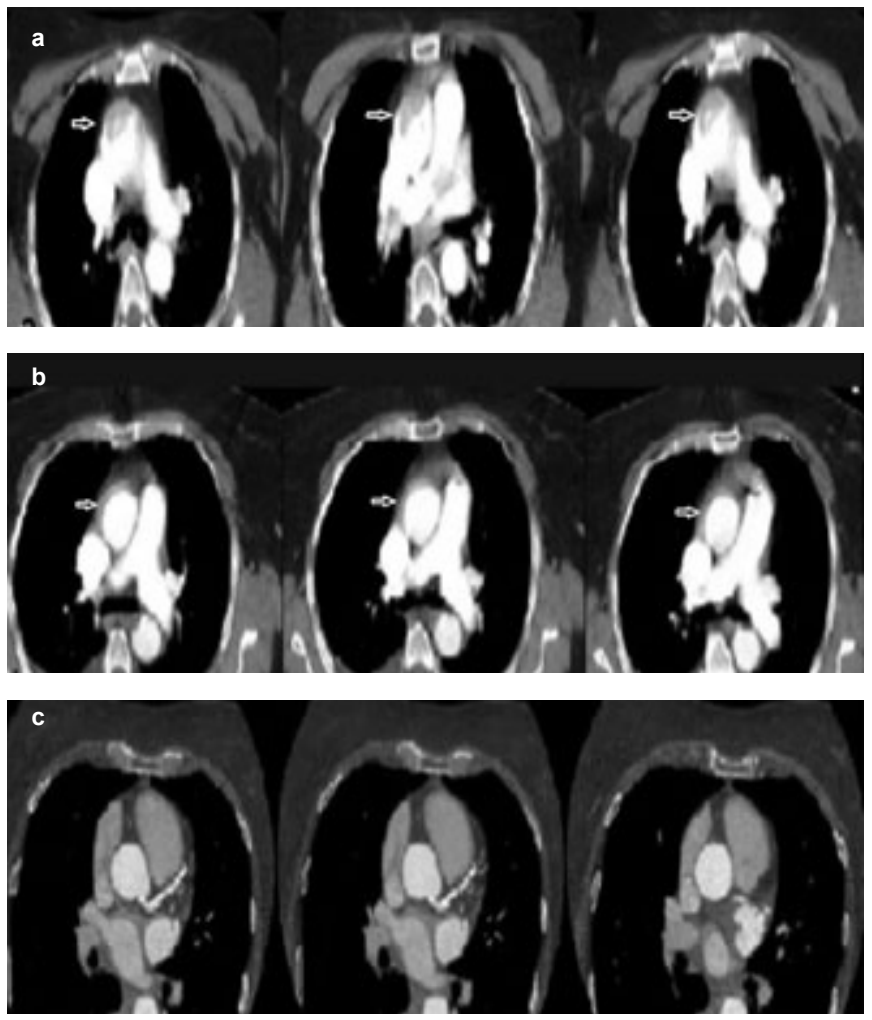

FIG. 4. a-c. CT immediately after $\mathrm{PCl}$. Intramural haematoma with contrast retention; the ascending aorta near the coronary orifice also had contrast retention in the false lumen and descending aorta was not involved (a). CT two days after PCl. Intramural haematoma at the ascending aorta had minimal contrast retention (b). CT demonstrated complete resolution of the false lumen after 3 months $\mathrm{PCl}$ (c).

were monitored conservatively, and only one patient was treated surgically. They reported that it would be useful to followup with $\mathrm{CT}$ after aorta-coronary stenting. CT may show the propagation of dissection and extra-aortic complications. The resolution of AD usually occurs between 48 hours and 3 months (9). Tanase et al. suggested performing CT imaging immediately and multi-detector CT imaging on the $2^{\text {nd }}$ day and after 1 week, when ACD is developed. CT imaging may be repeated after one or two months (8). As a result, ostial stenting of ACD in appropriate cases is less invasive when compared with surgery. In this case, we showed emergent stenting in appropriate cases in which ACD developed.

Ethics Committee Approval: Ethics committee approval was received for this case.

Informed Consent: Written informed consent was obtained from the patients for the publication of this case report and any accompanying images.

Peer-review: Externally peer-reviewed.

Author contributions: Concept - A.B., A.Ö.; Design - A.B, E.G., A.T.; Supervision - A.Ö, B.A., A.B.; Resource - A.B., A.Ö.; Materials - A.B., A.Ö., E.G.; Data Collection\&/or Processing - A.T., B.A.; Analysis\&/or Interpretation - A.B.; A.Ö.; E.G.; Literature Search - E.G., A.T., B.A.; Writing - A.B., A.Ö., E.G.; Critical Reviews - A.T., B.A.

Conflict of Interest: No conflict of interest was declared by the authors.

Financial Disclosure: The authors declared that this study has received no financial support.

\section{REFERENCES}

1. Perez-Castellano N, Garcia-Fernandez MA, Garcia EJ, Delcan JL. Dissection of the aortic sinus of Valsalva complicating coronary catheterization: Cause, mechanism, evolution, and management. Cathet Cardiovasc Diagn 1998;43:273-9.[CrossRef] 
2. Carstensen $\mathrm{S}$, Ward MR. Iatrogenic aorto coronary dissection: The case for immediate aorto ostial stenting. Heart Lung Circ 2008;17:325-9. [CrossRef]

3. Dunning DW, Kahn JK, Hawkins ET, O’Neill WW. Iatrogenic coronary artery dissection extending into and involving the aortic root. Cathet Cardiovasc Interv 2000;51:387-93.[CrossRef]

4. Pande AK, Gosselin G, Leclerc Y, Leung TK. Aortic dissection complicating coronary angioplasty in cystic medial necrosis. Am Heart $J$ 1996;131:1221-3.[CrossRef]

5. Goldstein JA, Casserly IP, Katsiyiannis WT, Lasala JM, Taniuchi M. Aortocoronary dissection complicating a percutaneous coronary intervention. J Invasive Cardiol 2003;15:89-92.

6. López-Mínguez JR, Climent V, Yen-Ho S, Gonzales-Fernandez R, Nogales-Asensio JM, Sanchex-Quintana D. Caracteristicas estructurales de los senos de Valsalva y porcion proximal delas arterias coronarias. Su relevancia durante la diseccion retrograde aortocoronaria. Rev Esp Cardiol 2006;59:696-702.[CrossRef]

7. Yip HK, Wu CJ, Yeh KH, Hang CL, Fang CY, Hesieh YK, et al. Unusual complication of retrograde dissection to the coronary sinus of Valsalva during percutaneous revascularization: a single-center experience and literatüre review. Chest 2001;119:493-501.[CrossRef]

8. Tanasie C, Chandonnet M, Chin A, Kokis A, Ly H, Perrault LP, et al. Catheter-induced aortic dissection after invasive coronary angiography: evaluation with MDCT. AJR Am J Roentgenol 2011;197: 1335-40. [CrossRef]

9. Kim JY, Yoon J, Jung HS, Yoo BS, Lee SH. Percutaneous coronary stenting in guide-induced aortocoronary dissection: angiographic and CT findings. Int $J$ Cardiovasc Imaging 2005;21:375-8.[CrossRef] 